\title{
DESIGN, ANALYSIS, AND TESTING OF A BLAST- RESISTANT BUILDING FAÇADE
}

\author{
T.R. BREWER, J.E. CRAWFORD, K.B. MORRILL \& J. ABRAHAM \\ Karagozian \& Case, Inc., USA.
}

\begin{abstract}
In a joint endeavor conducted for the US Department of State (DoS) Bureau of Diplomatic Security, $\mathrm{K} \& \mathrm{C}$ has developed curtain-wall technology for US government infrastructure overseas capable of withstanding the threats anticipated from large explosive events such as VBIEDs at close proximity. The analysis utilized high fidelity physics-based (HFPB) calculations based on a combination of computational fluid dynamics (CFD) and computational structural dynamics (CSD) modeling methods. Unlike many similar analysis and simulation efforts, this work was validated by a full-scale explosive test. This provided an opportunity to compare the calculation outputs with test data to determine the efficacy and accuracy of the calculation methods as well as providing indicators for further calibration of the analysis model. This paper will provide description and commentary of the calculation approach as adopted to analyze the structure using both CFD and CSD methods, as well as planning and conduct of the test including positioning of instrumentation and the purpose and nature of data collection. Comparison of the simulation and test data is accompanied by discussion of the most significant discrepancies and areas in which the calculations closely matched the observed calculation results. Finally, conclusions are presented regarding the efficacy of the calculational approach adopted and recommendations presented for future calculations, and testing of conventional structural systems that are to be subject to blast loading of this magnitude.
\end{abstract}

Keywords: analysis, blast protection, curtain wall, diplomatic security, façade, protective design, retrofit, testing, VBIED.

\section{INTRODUCTION}

Under a multi-year program directed by Mr. Russell J. Norris of the U.S. Department of State (DoS) Bureau of Diplomatic Security-working in conjunction with research partners from Karagozian \& Case, Inc. (K\&C); the Energetic Materials Research \& Testing Center (EMRTC) of New Mexico Tech University: Wiss, Janney, Elstner Associates, Inc. (WJE); and Physical Security LLC. A unique and highly effective blast-resistant, steel stud curtain wall (SSCW) has been developed. This building façade was developed primarily as a re-cladding option for existing building envelopes, although it can also be used for new construction. This curtain-wall system was designed in response to the DoS's need to reconcile security (physical, construction, and technical) while requiring operation and installation in potentially austere environments.

The SSCW system meets DoS requirements for forced entry (FE), small arms/ballistic resistance (BR), and blast protection while leveraging the advantages of prefabrication to produce a rapidly installable modular design. Utilizing a unitized 'cassette style' approach provides increased resilience and enables rapid repair and replacement of damaged sections. The cassette's nominal 60-in. width by 12 to 16-foot story-height facilitates shipment in standard 20-foot ISO containers and simplifies and speeds final installation.

This paper is part of the Proceedings of the $14^{\text {th }}$ International Conference on Structures Under Shock and Impact (SUSI 2016)

www.witconferences.com 


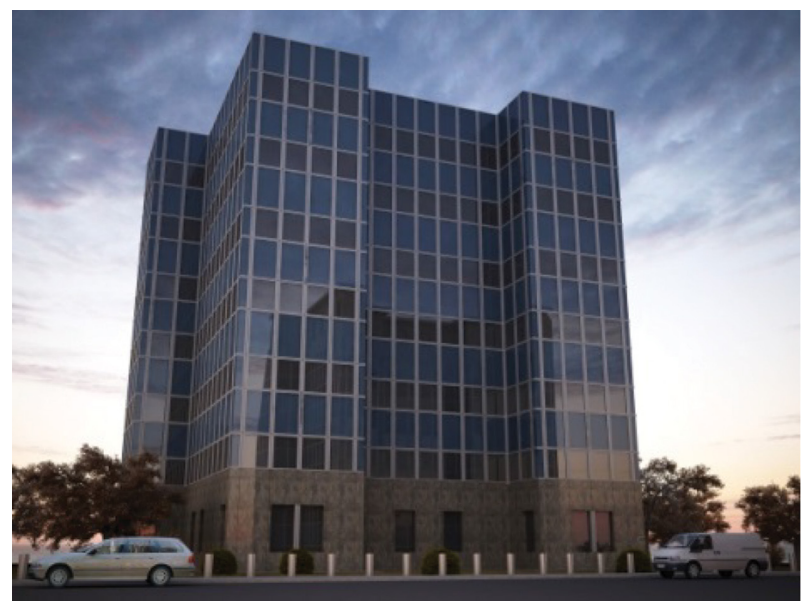

Figure 1: Example of an installation of the steel stud curtain wall described in the paper.

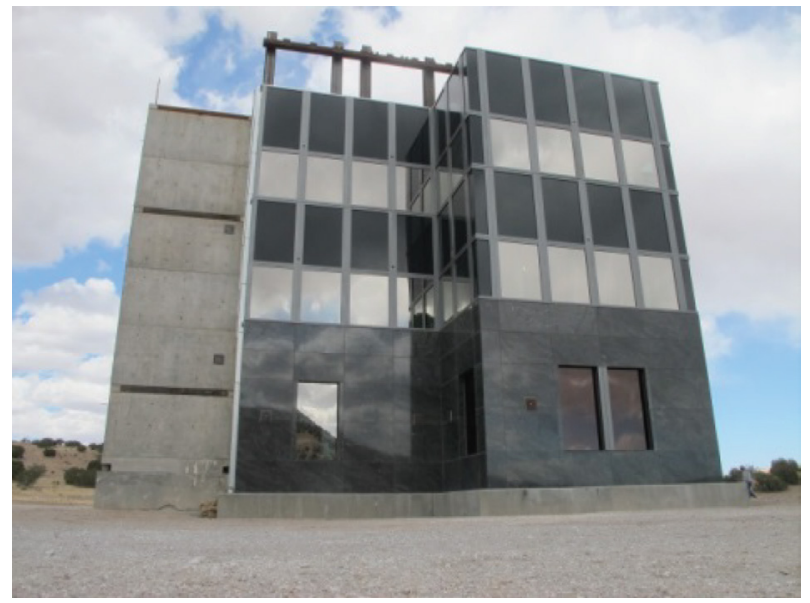

Figure 2: Full-scale test article and setup employed for blast tests.

An example of the SSCW as it would appear in an actual building façade is given in Fig. 1. A nearly identical configuration of the SSCW was tested at EMRTC to prove its merit, where it was subjected to a blast load of over 2,000 kPa-msec. This test article, which is limited in height to three stories, is shown in Fig. 2. Measurement and analytic results for this structure including the manner of its construction are discussed in the paper.

\section{BLAST-RESISTANT DESIGN}

The SSCW test structure accommodates a nominal $3.7 \mathrm{~m}$ floor-to-floor span, although this system is also adaptable for other story heights. The test structure was installed on a steelframed reaction structure; however, the concept is intended to be applicable to steel- or concrete-framed buildings. The work was intended to provide best practices and basis of design to allow subsequent projects to adapt and refine this technique to suit specific structures and project execution strategies. 


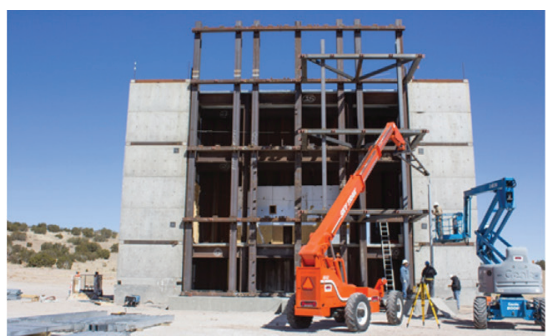

Test Reaction Structure

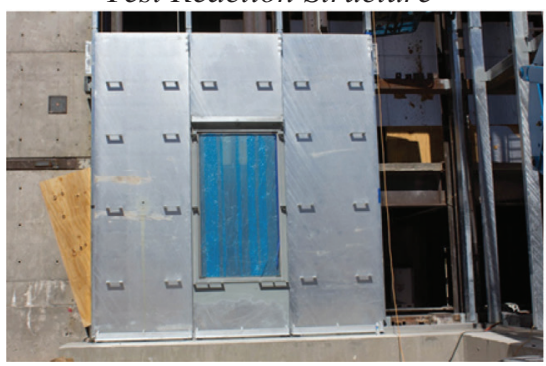

First floor cassette showing FE/BR window and ballistic steel plate prior to installation of granite cladding

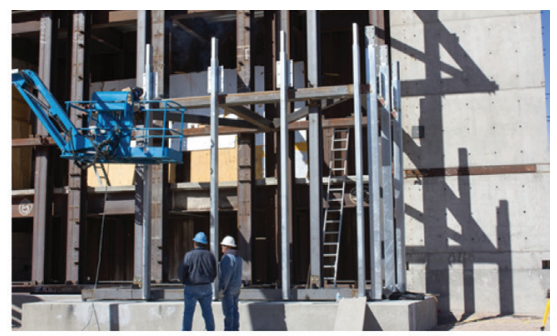

Installation of first floor mullions

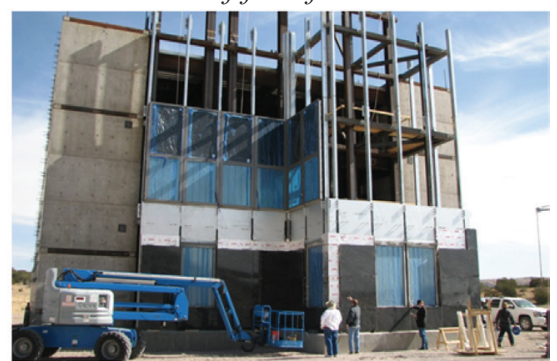

Installation of second floor cassettes

Figure 3: Installation of SSCW test structure.

Erection of the SSCW (Fig. 3) is initiated by installation of steel tube 'mullions' which span between and are anchored to the floor diaphragms of the structure. A vertical expansion/slip joint facilitates installation of the mullions and allows for vertical movement of the floor diaphragms. Gravity, seismic and wind loads are resisted by connections at each floor level. Blast loads are resisted by connections to the floor diaphragms, and rebound forces are resisted by unique 'rebound brackets' which engage the steel tube mullions. Once the mullion installation is complete, individual cassettes are then installed. For the test structure, the individual cassettes were clad in granite at the first floor level. Individual FE/BR windows were included on the ground floor, and strip blast-resistant windows were included on the second and third floors, with spandrel glass over the curtain-wall framing above and below the strip windows.

\section{BLAST LOADING}

Advanced analyses techniques were used by $\mathrm{K} \& \mathrm{C}$ in developing the blast- resistance component of the curtain-wall's design. Numerous calculations were made as part of the design effort to study the benefits of various design options. In the final calculational efforts leading up to the test, computational fluid dynamics (CFD) models were used to obtain the blast loadings striking the SSCW, which provided the loading employed in the CSD model. The CFD model is discussed below, while the highly detailed CSD model used to make the predictions of the curtain-walls performance is discussed in the next section.

\subsection{Pre-test predictions}

A final pre-test calculation was performed a few weeks before the blast tests to predict the response of the SSCW system as a means to validate the analytic models developed by $\mathrm{K} \& \mathrm{C}$ in developing the wall's blast-resistant design. 
3.1.1 CFD code and methodology

A CFD code was used to predict the blast pressure time-histories on the exterior surface of the curtain wall, which were recorded at a grid of tracer points on the surface representing the curtain wall in the CFD model. Rigid non-responding surfaces were used to represent the SSCW. The EOS used for air and the ANFO charges that were used in the blast tests are described below.

\subsubsection{EOS for air}

The air was modeled using a polytropic gas equation of state of the form (in indicial notation):

where,

$$
p=(\gamma-1) \rho\left[e-\frac{1}{2} v_{j} v_{j}\right]
$$

$\gamma=\quad$ Ratio of specific heats

$\rho=$ Density of air

$\mathrm{e}=\quad$ Specific total energy

$\mathrm{v}_{\mathrm{j}}=\quad$ Fluid velocity in the $\mathrm{x}, \mathrm{y}$, and $\mathrm{z}$-directions

The parameters used for this polytropic gas equation were consistent with the anticipated atmospheric conditions present at the test site in Socorro, NM on the day of test. The energy, density and ratio of specific heats specified for the ambient conditions provide a pressure of $81 \mathrm{kPa}$, which is consistent with the elevation of approximately $1,890 \mathrm{~m}$ at the test site.

\subsubsection{ANFO EOS}

The ANFO charge was modeled using a programmed burn and the Jones-Wilkins Lee (JWL) EOS. The parameters required to model ANFO in this manner are: (1) HE density, (2) Chapman-Jouguet (C-J) pressure, (3) C-J detonation velocity, and (4) JWL fit parameters. The parameters used to model ANFO were obtained from Davis and Hill (2001), as follows:

$$
\begin{aligned}
& \mathrm{R} 0=0.931\left(\text { density, } \mathrm{gm} / \mathrm{cm}^{3}\right) \\
& \mathrm{A}=49.46 \mathrm{e} 10 \text { dynes } / \mathrm{cm}^{2} \\
& \mathrm{~B}=1.891 \mathrm{e} 10 \text { dynes } / \mathrm{cm}^{2} \\
& \mathrm{R} 1=3.907 \\
& \mathrm{R} 2=1.118
\end{aligned}
$$

$$
\begin{aligned}
\omega & =1 / 3 \\
\text { DCJ } & =4.16 \mathrm{e} 5 \mathrm{~cm} / \mathrm{s} \\
\text { PCJ } & =5.15 \mathrm{e} 10 \text { dynes } / \mathrm{cm}^{2} \\
\mathrm{E} 0 & =2.484 \mathrm{e} 10 \text { dynes } / \mathrm{cm}^{2}
\end{aligned}
$$

\subsubsection{CFD mesh and geometry}

A large CFD domain was required to conduct the CFD analysis which needed to be sufficiently large to encompass the SSCW structure and provide adequate space around the charge to allow the expansion of the detonation products. Accuracy consideration demands a CFD mesh resolution that is sufficiently small to adequately capture shock fronts and the shock propagation through the domain. To reduce the computational effort the CFD problem was divided into an initial calculation, in which the mesh resolution is high near the charge during the detonation of the explosive. Once the programmed burn was completed, the CFD solution was remapped to a uniform mesh which was used for the rest of the CFD calculation. A cut-plane in the CFD domain (Fig. 4) is used to depict the element resolutions in the initial and remap meshes. The initial mesh is composed of 18 million tetrahedral elements and provides an element resolution of 0.5 -in near the charge. The remap mesh is 


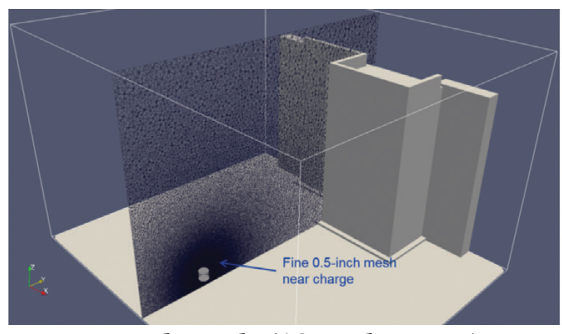

Initial Mesh (18M elements)

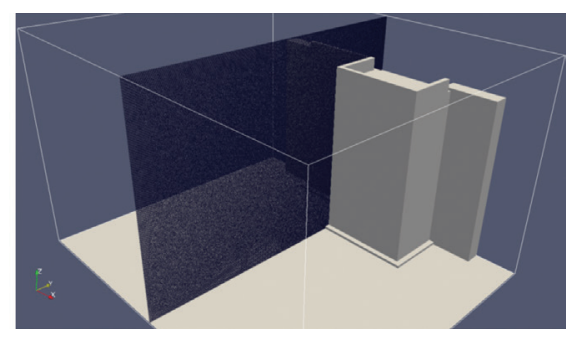

Remap Mesh (115M elements)

Figure 4: Mesh resolutions for CFD domain.

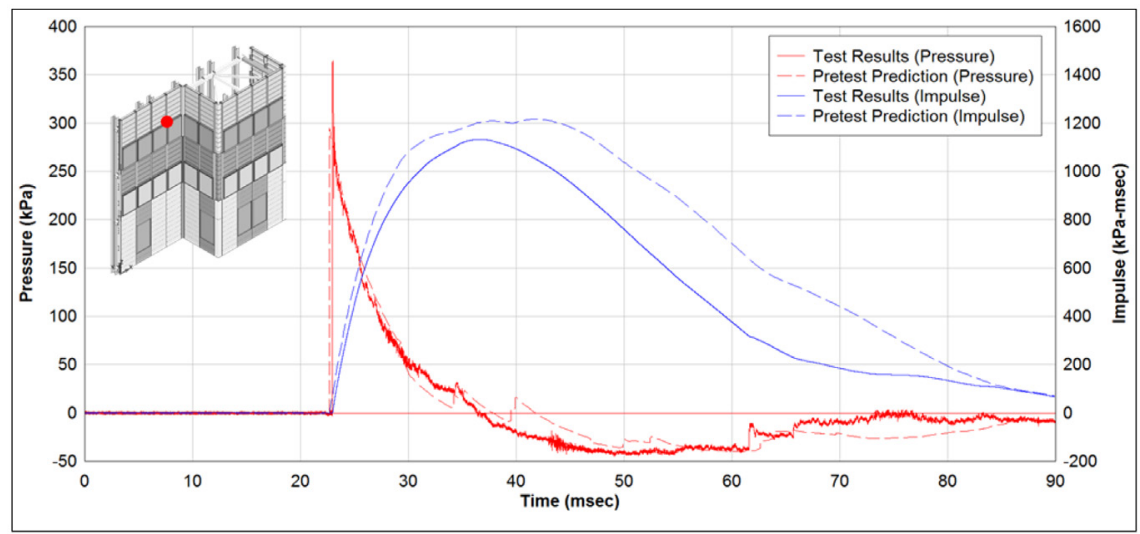

Figure 5: Pressure gage comparison with test data for gages on the SSCW.

composed of 115 million tetrahedral elements and provides an element resolution of $3.5 \mathrm{in}$. across the domain.

Outflow boundary conditions were used for all the surfaces in the CFD model except for the ground and the SSCW surfaces. The ground and SSCW surfaces were modeled using reflecting boundary conditions that are representative of a rigid non-responding surface, which allows the adjacent fluid to move tangentially to the surface but does not allow flow through the surface. Figure 4 shows the reflecting outflow surfaces from two different views; the clear surfaces are outflow planes while all the grey surfaces are reflecting surfaces.

\subsection{Comparison with test data}

A pressure and impulse time-history plot for a single gage location is shown in Fig. 5 along with the corresponding gage data from the test. The computational results showed good agreement with the test results for the 'time of arrival' and, in general, for the pressure and impulse time-histories. 


\section{STRUCTURAL RESPONSE}

\subsection{Pre-test predictions}

A CSD code was used to simulate the response of the SSCW to the blast load. The model was developed by combining the SSCW components into an assembled model of the test article (Fig. 6).

\subsection{Comparison with test data}

In general, observations during the test and responses gathered from the gages were consistent with those anticipated. Even though some gages were rendered inoperative during the test, the remaining time-histories of displacement, pressure, and strain garnered from the test were consistent with the analysis and the design itself.

Comparisons of calculation and test results for displacement gages X1, X3, and X5 are shown in Fig. 7. In general, with the exception of Gage X1, on the first floor, the records compare favorably in magnitude and wave shape. However, the first floor Gage X1 peak is about twice the prediction, although both records show a rebound to a relatively small late time deflection. Part of this difference is due to the under prediction of blast load which were approximately $15 \%$ lower than the actual test results in some areas. Another factor in the larger measured deflections is the extensive localized yielding in the support beam that was observed at the places where the plates attaching the curtain-wall's mullions to it were located. The support beam is intended to represent the floors of an actual building (i.e., their noncompliance). The upper floor displacements are much smaller and show a consistent behavior between the measured and predicted responses and no localized response of the support structure.

\subsection{Internal environment}

The interior environment created by the blast event, and the potential implications for the occupants and contents of a building with this reclad design, is a key metric in evaluating

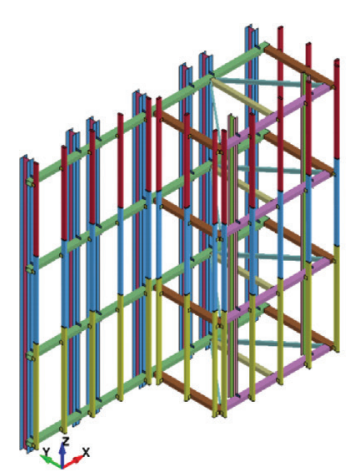

Support Structure with SSCW Vertical Mullions Attached

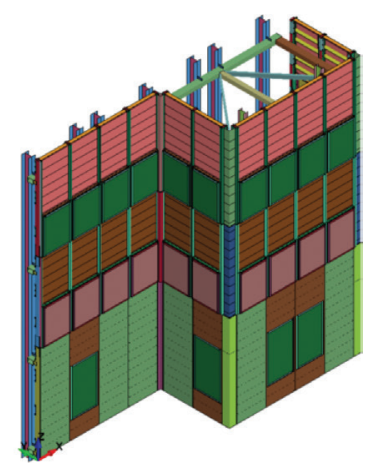

SSCW Cassettes Installed

Figure 6: CSD analysis model details. 


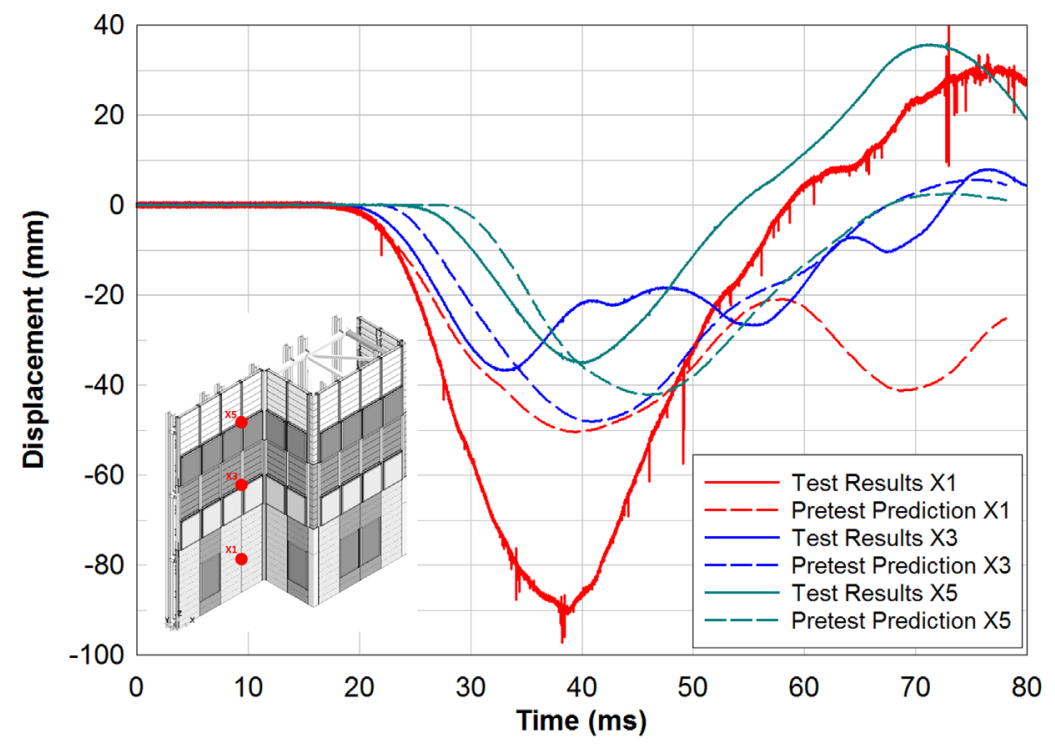

Figure 7: Displacement Gages X1, X3, X5.

the efficacy of the blast mitigation properties of SSCW system. Considerable structural deformations (short of catastrophic failure) are permitted as long as the effects on the internal environment are sufficiently mitigated. Several measurement systems were employed to achieve this. First, a series of high-speed cameras were positioned inside the SSCW envelope at each floor level to record the response of the SSCW and, second, pressure gages were installed to measure the airblast effects inside the SSCW envelope. These active measurements were supplemented by post-test documentary photos of the interior.

The peak pressures measured within the structure during the blast were generally less than $7 \mathrm{kPa}$, with the exception of a $9.5 \mathrm{kPa}$ peak at around $200 \mathrm{~ms}$ (see Fig. 8). This higher peak may have been due to the failure of one of the FE/BR window frames adjacent to the peak value gage, which was improperly installed.

The debris entering the interior space behind the structure, resulted, primarily, from low-velocity window trim pieces and insulation from the SSCW. The only exception being the debris from the failed FE/BR window frame (mentioned above), from which a heavy frame member was propelled into the interior space. In this regard, the post-test inspection of this frame found that some of the bolts holding the frame to the cassette were not installed, which significantly weakened the window and allowed injurious debris to enter the interior.

The FE/BR frame and trim pieces separating from the SSCW are clearly visible in a frame from the high-speed video taken during the positive phase of the response (Fig. 9). The trim pieces entering the occupied space offers another reminder that due regard should be given to such items as plastic and wood trim to minimize its potential for causing injury if it becomes debris. Very little debris was seen at the 3rd floor as evidenced by a similar high-speed camera frame of the 3rd floor (Fig. 9). 


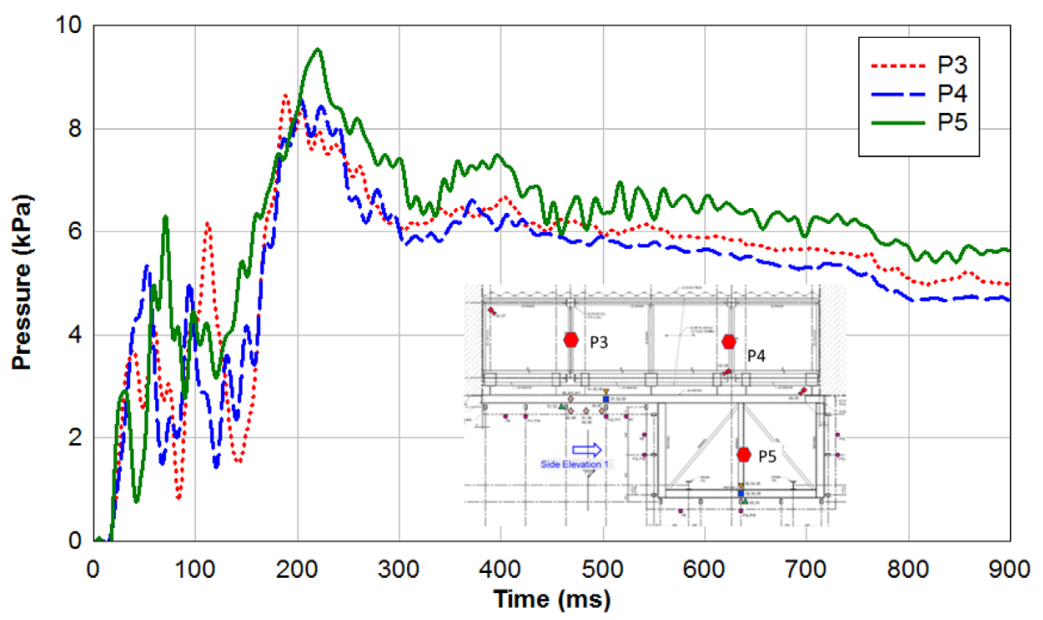

Figure 8: Internal pressures behind SSCW.
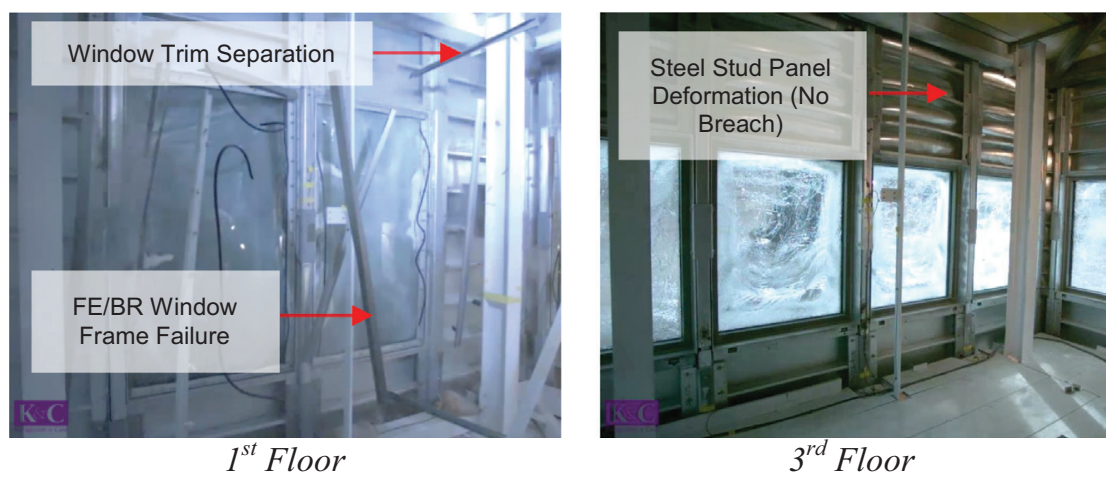

Figure 9: Internal views during the positive phase of the blast.

\subsection{Comparison of curtain wall pre- and post-blast}

Damage to the exterior of the SSCW during the test included fragmentation and removal of the granite cladding, blast window cracking (break safe), and failure of the spandrel glass with the supporting steel stud panels left intact. K\&C's design philosophy for the spandrel glass was to allow it to fail and just catch the debris with a thin steel plate attached to the mullions, which worked well. This allows this component of the SSCW to be made conventionally, affording a considerable reduction in costs. Comparison of the condition of the SSCW pre- and post-test, shown in Fig. 10.

\section{CONCLUSIONS}

This paper explained the SSCW curtain-wall design effort needed to fabricate and test an innovative but practical SSCW design to withstand the many blast threats considered in 


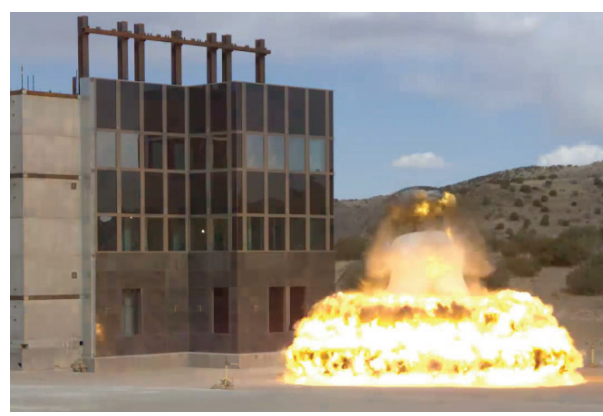

Detonation

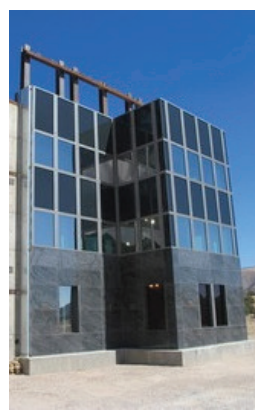

Pretest

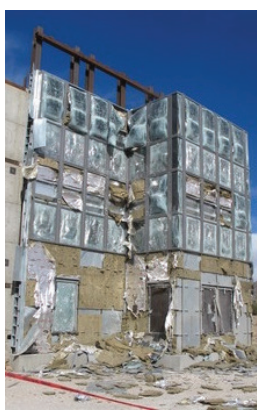

Posttest

Figure 10: Pre-test and post-test exterior views of SSCW.

designing curtain walls for DoS facilities. The SSCW design effort described was validated in its performance against the design basis threat (DBT), which emanated from VBIEDs at standoff distances much less than those normally considered by DoS. Detailed pre-test predictions of the structural response and airblast loading were performed using state of the art CSD and fluid dynamics analysis codes and models. The structural response of the SSCW test structure was captured using an extensive suite of active instrumentation, which captured key details of structural response and airblast loading, as well as high-speed video coverage of the exterior and interior of the structure.

The initial benefit of this endeavor for the protective design community is the data and lessons captured from the analyses and testing conducted. This experience will be made available as a set of openly available engineering drawings. These will provide a basis for adapting the SSCW design to specific buildings and environmental conditions, while ensuring that final system meets the blast, small arms/ballistic and FE requirements of the DoS DBT.

\section{REFERENCES}

[1] Beckhard, H., The breuer-beckhard precast facades. Exterior Wall Systems: Glass and Concrete Technology, Design and Construction, ASTM STP 1034, ed. B. Donaldson, American Society for Test and Materials: Philadelphia, PA, pp. 154-169, 1991.

[2] Boyd, J.M., Over-cladding of aluminum framed curtainwalls and skylights building exterior wall systems. Journal of ASTM International, 4(10), pp. 139-153, 2007. http://dx.doi.org/10.1520/JAI100863

[3] Clift, C.D., Curtain wall designs for wind and blast: three case studies. Journal of Architectural Engineering, 12(3), pp. 150-155, 2006.

http://dx.doi.org/10.1061/(ASCE)1076-0431(2006)12:3(150)

[4] Crawford, J.E., Lan, S., Ferritto, J.M. \& Liu, C., Blast Effects Analysis of Glazing Façade of Terminal 3 at Singapore Changi Airport, Karagozian \& Case: Burbank, CA, 2005.

[5] Crawford, J.E., Lan, S., Liu, C. \& Ong, D., Basis of Development for the Glazing Analysis Software BEA_CW, Volume I, Karagozian \& Case: Burbank, CA, and K\&C Protective Technologies Pte Ltd: Singapore, 2008. 
[6] Crawford, J.E. \& Lan, S., Design and Analysis of Blast-Resistant Curtain Walls, Karagozian \& Case: Burbank, CA, and K\&C Protective Technologies Pte Ltd: Singapore, 2007.

[7] Crawford, J.E., Lan, S. \& Dunn, B.W., Cable catcher systems for improving blast resistance of glazing façades. Proceedings of the 19th Military Aspects of Blast and Shock Symposium, Alberta: Canada, 2006.

[8] Crawford, J.E., Lan, S., Fu, S., Der Avanessian, H. \& Palermo, D., Advances in blastresistant glazing. For the MABS 20 International Symposium on Military Aspects of Blast and Shock, Oslo, Norway, 2008.

[9] Davis, L.L. \& Hill, L.G., ANFO cylinder tests. CP620 Shock Compression of Condensed Matter, 2001.

[10] Freedman, S., Architectural precast concrete: a material for the 21st century. Exterior Wall Systems: Glass and Concrete Technology, Design and Construction, ASTM STP 1034, ed. B. Donaldson, American Society for Test and Materials: Philadelphia, PA, pp. 131-153, 1991.

[11] Horowitz, J.M., The interrelation of exterior wall and structural systems in buildings. Exterior Wall Systems: Glass and Concrete Technology, Design and Construction, ASTM STP 1034, ed. B. Donaldson, American Society for Test and Materials: Philadelphia, PA, pp. 5-23, 1991.

[12] Lawrence, J.B., Evaluation, recommendations, and implementation for overcladding the tower plaza condominium. Proceedings, Symposium on Building Envelope Technology, Detroit, MI, pp. 87-96, 2008.

[13] Lawrence, J.B. \& Johnson, P.G., Envelop remediation-a case study in support of an over-cladding approach. Building Exterior Wall Systems, Journal of ASTM International, 5(10), pp. 121-138, 2008. http://dx.doi.org/10.1520/JAI100885

[14] Li, S.S. \& McClelland, N., Façade renovation of the wexner center for the arts, building exterior wall systems. Journal of ASTM International, 4(9), pp. 154-160, 2007. http://dx.doi.org/10.1520/JAI100870

[15] Lindow, E.S. \& Jasinski, L.F., Panelized wall construction: design, testing, and construction procedures. Performance of Exterior Building Walls, ASTM STP 1422, ed. P.G. Johnson, American Society for Test and Materials: West Conshohocken, PA, pp. 231-241, 2003.

[16] Norville, H.S. \& Conrath, E.J., Blast-resistant glazing design. Journal of Architectural Engineering, 12(3), pp. 129-136, 2006.

http://dx.doi.org/10.1061/(ASCE)1076-0431(2006)12:3(129)

[17] Sakhnosky, A.A., Full-scale performance testing of curtain walls. Exterior Wall Systems: Glass and Concrete Technology, Design, and Construction, ASTM STP 1034, ed. B. Donaldson, American Society for Test and Materials: Philadelphia, PA, pp. 47$58,1991$.

[18] Schwartz, T., Glass and metal curtain-wall fundamentals. JSTOR. Version Vol. 32, No. 1, Curtain Walls (2001). Association for Preservation Technology International (APT), Web. 6 Aug. 2010, available at http://www.jstor.org/stable/1504691

[19] Yeomans, D., The origins of the modern curtain wall. JSTOR. Version Vol. 32, No. 1, Curtain Walls (2001), Association for Preservation Technology International (APT), n.d. Web. 10 Aug. 2010, available at http://www.jstor.org/stable/1504688 